\section{Broncho-oesophageal fistula treated effectively without surgical resection}

\author{
G W Parry, Ali Juma, J E Dussek
}

\begin{abstract}
A patient with an oesophagobronchial fistula who was unfit for surgery was treated successfully by the application of sclerosants (sodium hydroxide and acetic acid) to the oesophageal and bronchial ostia of the fistula.
\end{abstract}

(Thorax 1993;48:189-190)

Congenital broncho-oesophageal fistula is an uncommon clinical problem; a recent review found around 100 cases published worldwide. The usual treatment is resection via thoracotomy, but in the case we report here the condition was managed effectively without the need for pulmonary resection.

\section{Clinical report}

A 72 year old man was referred with a 10 year history of intractable cough following the ingestion of fluids. There were no other relevant aspects of the history. Physical examination revealed no abnormalities and examination of the cardiovascular and respiratory systems showed nothing remarkable, though exercise tolerance was very poor.

A posteroanterior chest radiograph was unremarkable, but a barium swallow examination (figure) showed a smooth fistula between the mid oesophagus and the bronchus intermedius, with contrast flowing into rather ectatic right lower lobe bronchi. No other abnormalities were seen.

At bronchoscopy the bronchial tree appeared normal, apart from a small "nodule" with surrounding erythema in the proximal bronchus intermedius. Oesophagoscopy also showed mostly normal appearances, apart from a small "diverticular" area on the right at $27 \mathrm{~cm}$, a biopsy specimen of which showed normal oesophageal mucosa.

These abnormal areas were thought to be the bronchial and oesophageal ostia of the broncho-oesophageal fistula seen on the contrast radiograph. Both were painted with $10 \%$ sodium hydroxide solution followed by a $30 \%$ acetic acid solution via the bronchoscope and oesophagoscope.

After this the patient was able to swallow without having symptoms. He remained well until 18 months after the procedure, when he developed similar symptoms of cough following fluid ingestion. A chest radiograph was again unremarkable; a repeat barium swallow was normal. Bronchoscopy showed nothing remarkable but oesophagoscopy again showed a small diverticular area at $28 \mathrm{~cm}$. Sodium hydroxide and acetic acid were applied to this area again.

The patient remains well with no symptoms two and a half years later.

\section{Discussion}

A fistula between the respiratory tract and the upper gastrointestinal tract is most commonly a tracheo-oesophageal fistula with or without oesophageal atresia. The quoted incidence is about 1:4000 births. ${ }^{1}$ Fistula into the more distal bronchial tree (broncho-oesophageal fistula) is considerably more rare.

The aetiology of many of these cases of broncho-oesophageal fistula remains speculative, though some cases are neoplastic, inflammatory, or traumatic in origin. Some,

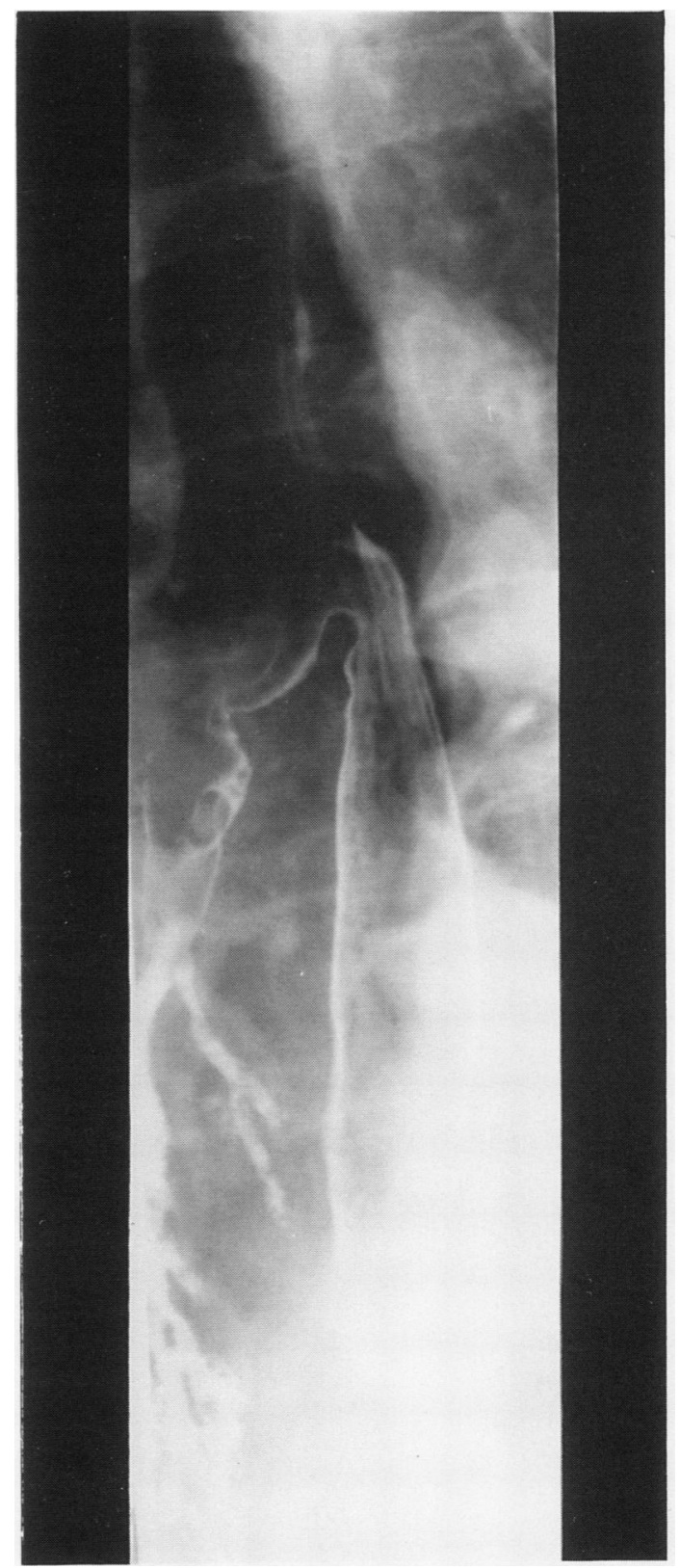

Barium swallow showing a broncho-oesophageal fistula between the oesophagus and the bronchus intermedius. 
however, appear to be congenital. A recent review of 100 cases of broncho-oesophageal fistula found that fistulas into the right lung are much more common than those into the left lung, though no explanation for this is apparent.

Patients invariably present with cough that follows ingestion of fluid and the diagnosis of broncho-oesophageal fistula is frequently delayed. Many patients do not begin to develop symptoms until their middle years, though it is not clear why a congenital problem should take so long to cause symptoms (sometimes as long as 50 years $^{3-5}$ ). Possible explanations include an initially upwardly directed fistula track and the presence of small mucosal folds covering the ostia of the fistula. ${ }^{3}$

Once the diagnosis is considered possible, it is confirmed most effectively by contrast radiology supplemented by bronchoscopy and oesophagoscopy. A standard posteroanterior chest radiograph is seldom helpful.

The management of a broncho-oesophageal fistula is usually surgical with thoracotomy, closure of the fistula, and simultaneous resection of the affected lung. ${ }^{246}$ In the occasional patient who is unfit for or declines thoracotomy and pulmonary resection there is a place for more conservative treatment with tissue sclerosants, such as silver nitrate ${ }^{7}$ or sodium hydroxide. Sodium hydroxide was effective in this patient, who was considered unfit for pulmonary resection, and the procedure can if necessary be repeated should symptoms recur.

Thus, although the definitive treatment of broncho-oesophageal fistula is surgical resection, low morbidity procedures, such as that described here, can produce a satisfactory result in patients unfit for pulmonary resection, and may be a suitable treatment for this unusual clinical problem.

1 Wright VW. Oesophageal atresia. Br $\mathcal{f}$ Hosp Med 1989; 42:452-60.

2 Risher WH, Arensman RM, Ochsner JL. Congenital broncho-oesophageal fistula. Ann Thorac Surg 1990;49. $500-5$.

3 Braimbridge MV, Keith HI. Oesophageo-bronchial fistula in the adult. Thorax 1965;20:226-33.

4 Osinowo O, Harley HRS, Janigan D. Congenital bronchooesophageal fistula in the adult. Thorax 1983;38: 138-42.

5 Smith BD Jr, Mikaelian DO, Cohn DE. Congenital broncho-oesophageal fistula in the adult. Ann Otol Rhinol Laryngol 1987;96:65-7.

6 Kameya S. Congenital broncho-oesophageal fistula in the adult. Am $\mathcal{F}$ Gastroenterol 1984;79:569-72.

7 Clerf LH. Broncho-oesophageal fistula; report of a case. Ann Otol 1933;42:920-2. 